\title{
$\begin{array}{r}\text { WAGENINGEN } \\ \text { UNIVERSITY \& RESEARCH } \\ \hline\end{array}$
}

\section{Extraction methods and food uses of a natural red colorant from dye sorghum}

Akogou, F. U., Kayodé, A. P., den Besten, H. M., \& Linnemann, A. R.

This article is made publically available in the institutional repository of Wageningen University and Research, under article $25 \mathrm{fa}$ of the Dutch Copyright Act, also known as the Amendment Taverne.

Article $25 \mathrm{fa}$ states that the author of a short scientific work funded either wholly or partially by Dutch public funds is entitled to make that work publicly available for no consideration following a reasonable period of time after the work was first published, provided that clear reference is made to the source of the first publication of the work.

For questions regarding the public availability of this article, please contact openscience.library@wur.nl.

Please cite this publication as follows:

Akogou, F. U., Kayodé, A. P., den Besten, H. M., \& Linnemann, A. R. (2018). Extraction methods and food uses of a natural red colorant from dye sorghum. Journal of the Science of Food and Agriculture, 98(1), 361-368. https://doi.org/10.1002/jsfa.8479 


\title{
Extraction methods and food uses of a natural red colorant from dye sorghum
}

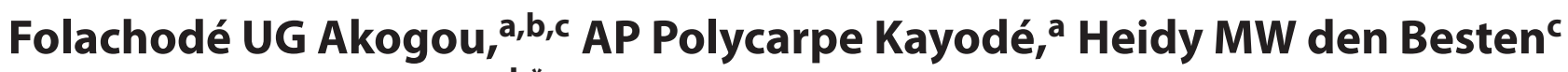 \\ and Anita R Linnemann ${ }^{b *}{ }_{\odot}$
}

\begin{abstract}
BACKGROUND: The interest in stable natural colorants for food applications continues to grow. A red pigment extracted from the leaf sheaths of a sorghum variety (Sorghum bicolor) with a high content of apigeninidin is widely used as a biocolorant in processed foods in West Africa. This study compared the colour and anthocyanin composition from traditional extraction methods to determine options for improvement and use of the red biocolorant from dye sorghum in the food sector.

RESULTS: Sorghum biocolorant was commonly applied in fermented and heated foods. Traditional extraction methods predominantly differed in two aspects, namely the use of an alkaline rock salt (locally known as kanwu) and the temperature of the extraction water. Cool extraction using the alkaline ingredient was more efficient than hot alkaline and hot aqueous extractions in extracting anthocyanins. The apigeninidin content was three times higher in the cool and hot alkaline extracts than in the aqueous extract.
\end{abstract}

CONCLUSION: Cool and hot alkaline extractions at pH 8-9 were the most efficient methods for extracting apigeninidin from dye sorghum leaf sheaths. Broader use of the sorghum biocolorant in foods requires further research on its effects on nutrient bioavailability and antioxidant activity.

(c) 2017 Society of Chemical Industry

Keywords: dye sorghum; extraction; 3-deoxyanthocyanidins; anthocyanins; apigeninidin; porridge

\section{INTRODUCTION}

Colour is important in consumer acceptance of food products. ${ }^{1}$ Consumers are sensitive to food colour because it gives information on freshness, safety and sensory characteristics. ${ }^{1,2}$ Many consumers prefer natural colorants because of growing concerns about synthetic colorants. ${ }^{1}$ Unfortunately, many natural colorants are not stable in their applications in food products, ${ }^{3}$ for instance because they are sensitive to heat treatment. Therefore the dyeing industry is continuously looking for underutilised pigmented plants as new sources of stable colorants. ${ }^{4}$ In West Africa, mature leaf sheaths harvested from dye sorghum (Sorghum bicolor) plants are used fresh or dried for food colouring purposes. ${ }^{4}$ The red pigment extracted from dye sorghum leaf sheaths is a rich source of 3-deoxyanthocyanidins, ${ }^{5}$ a rare class of natural pigments. ${ }^{6}$ Like most anthocyanins, the 3-deoxyanthocyanidins have an aglycon as base structure, which is bound to sugar moieties or hydroxyl and methoxyl groups. ${ }^{7}$ The absence of a hydroxyl group at the $\mathrm{C}-3$ position of the aglycon is the main structural difference between 3-deoxyanthocyanidins and common anthocyanins. ${ }^{8}$ Extracts of 3-deoxyanthocyanidins are characterised by (a) good stability to acidulants and $\mathrm{pH}$ changes, ${ }^{9,10}$ (b) resistance of their dimeric forms (i.e. the apigeninidin-flavene dimer and the apigenin-7-O-methylflavene dimer) to nucleophilic and hydrophilic attacks by sulfite, ${ }^{11}$ (c) improved colour stability in the presence of co-pigments, ${ }^{8}$ (d) slow chalcone formation and ring opening when exposed to heat treatments, ${ }^{12}$ and (e) their antioxidant activity. ${ }^{5}$ Consequently, extracts from dye sorghum leaf sheaths could be a potentially interesting source of a red colorant for food applications when the use of anthocyanins is restricted owing to their instability in certain food processing conditions (e.g. with respect to $\mathrm{pH}$, bleaching agents and temperature). ${ }^{11,13,14}$ The red watery extract from sorghum leaf sheaths is obtained by trituration or boiling, with or without using an alkaline rock salt named kanwu, kanwa or trona in West Africa. ${ }^{15}$ However, the specific conditions of the different extraction methods and the impact of these conditions on the characteristics of the obtained extracts have not been studied. Kanwu is a mixture of carbonate and bicarbonate salts with sodium and potassium as monovalent ions and calcium, magnesium and iron as divalent ions. ${ }^{16}$ In Benin, the applications of the watery extract of sorghum leaf sheaths include its use for decorative purposes. ${ }^{2}$ Food applications of the biocolorant encompass its use in liquid foods such as koko, a fermented cereal-based porridge, as well as in solid foods such as

\footnotetext{
Correspondence to: AR Linnemann, Food Quality and Design, Wageningen University, Wageningen, The Netherlands. E-mail: anita.linnemann@wur.nl

a Laboratory of Valorization and Quality Management of Food Bio-Ingredients (LaBio), DNSA/FSA, Université d'Abomey-Calavi, Cotonou, Benin

b Food Quality and Design, Wageningen University, Wageningen, The Netherlands

c Laboratory of Food Microbiology, Wageningen University, Wageningen, The Netherlands
} 
wagashi, a West African soft cheese obtained by coagulating cow's milk with juice from Calotropis procera leaves. ${ }^{5,17,18}$

To date, no comparative data are available on how the biocolorant is traditionally extracted and how it is used for colouring foods. This study therefore evaluates local knowledge on the extraction methods of the colorant and its application in a model food that undergoes a sequence of processing steps, namely koko, followed by an analysis in the laboratory of the pigment profiles that result from different traditional extraction methods. The aim is to determine the extraction methods that are currently being used and compare the anthocyanin profile and colour characteristics of the dye extracts obtained by these methods with a view to improve the extraction and to assess the potential applications of sorghum biocolorant in the industrial food sector in developed countries.

\section{MATERIALS AND METHODS}

\section{Field survey}

Study area

The study was carried out in three towns of Benin, i.e. Parakou (latitude $9^{\circ} 15^{\prime} \mathrm{N}$ to $9^{\circ} 29^{\prime} \mathrm{N}$, longitude $2^{\circ} 26^{\prime} \mathrm{E}$ to $2^{\circ} 44^{\prime} \mathrm{E}$ ) and Natitingou (latitude $10^{\circ} 10^{\prime} \mathrm{N}$ to $10^{\circ} 26^{\prime} \mathrm{N}$, longitude $1^{\circ} 12^{\prime} \mathrm{E}$ to $1^{\circ} 31^{\prime} \mathrm{E}$ ), both in the northern part of Benin, and Dassa-Zoumè (latitude $7^{\circ} 44^{\prime} \mathrm{N}$ to $7^{\circ} 52^{\prime} \mathrm{N}$, longitude $2^{\circ} 3^{\prime} \mathrm{E}$ to $2^{\circ} 15^{\prime} \mathrm{E}$ ), in the centre of the country. These communities were selected because dye sorghum is grown there and commonly used for food applications.

\section{Survey}

From the three communities (Parakou, Natitingou and Dassa-Zoumè), data on the extraction of dye sorghum biocolorants were collected from 180 processors of dyed foods. For the application of dye sorghum colorant in fermented foods, data were collected from 90 processors of dyed koko using a questionnaire including the unit processes and the ingredients needed to extract and apply the colorant in koko. The questionnaires were in the local languages and conducted by two experienced interviewers in each community. The interviewers were trained during a 1 day session, and test interviews were held to assure that the questionnaire was well understood and administered correctly. The processors were randomly chosen. They were aged from 16 to 67 years and were only women, since in Benin women are the main actors in the food processing sector. ${ }^{19}$

\section{Physicochemical analysis}

Samples from the field and their pre-treatment

Samples of dye sorghum leaf sheaths and dyed koko were bought from local markets in Parakou, Natitingou and Dassa-Zoumè, packed in an ice box and transported to the laboratory. The samples of dyed koko were dried at $50^{\circ} \mathrm{C}$ for $24 \mathrm{~h}$ and ground into powder. Dried porridge powder was used to extract the phenolic compounds. The samples of dye sorghum leaf sheaths were ground using a miller (Coffee Bean and Spice Mill Grinder Model \#843, Moulinex, Bagnolet, France) and the derived powder was used to extract the phenolic compounds.

\section{Experimental design}

The traditional methods to extract biocolorants from the leaf sheaths of dye sorghum were assessed for the total phenolic and anthocyanin contents as well as for their colour parameters. All three extraction methods resulting from the survey were studied. These were cool alkaline extraction, hot alkaline extraction and hot aqueous extraction. Processors were chosen according to the method they used to extract the colorant from sorghum leaf sheaths. Another batch of dye sorghum leaf sheaths and one batch of kanwu were bought from a local market in Dassa-Zoumè. The mean values of the total phenolic content (TPC) and anthocyanin content $(A C Y)$ of this sample of dye sorghum leaf sheaths were 130.7 and $28.7 \mathrm{mg} \mathrm{g}^{-1}$ respectively. A quantity of $50 \mathrm{~g}$ of dye sorghum leaf sheaths was extracted by triplicate processors for each extraction scenario. Samples of watery extracts and residues of leaf sheaths after extraction were taken at different process steps and transported to the laboratory. The residues of leaf sheaths collected after extraction were dried at $50^{\circ} \mathrm{C}$ for $24 \mathrm{~h}$ and ground into powder. The TPC non-extracted (TPC $\left.{ }_{n e}\right)$ and $A C Y$ non-extracted $\left(A C Y_{n e}\right)$ by the traditional extraction methods were determined by measuring the TPC and ACY contents of the residues of the leaf sheaths. The percentages of $T P C_{n e}\left(\% T P C_{n e}\right)$ and $A C Y_{n e}\left(\% A C Y_{n e}\right)$ were calculated with Eqns (1) and (2).

$$
\% \mathrm{TPC}_{\mathrm{ne}}=\left(\mathrm{TPC}_{\text {residues }} / 130.7\right) \times 100
$$

where $\% \mathrm{TPC}_{\mathrm{ne}}$ is the percentage of TPC non-extracted using the traditional method, TPC residues $\left(\mathrm{mg} \mathrm{g}^{-1}\right)$ is the TPC of the residues of dye sorghum leaf sheaths and $130.7\left(\mathrm{mg} \mathrm{g}^{-1}\right)$ is the TPC of the dye sorghum leaf sheaths.

$$
\% A C Y_{\text {ne }}=\left(A C Y_{\text {residues }} / 28.7\right) \times 100
$$

where $\% \mathrm{ACY}_{\text {ne }}$ is the percentage of ACY non-extracted using the traditional method, $A C Y_{\text {residues }}\left(\mathrm{mg} \mathrm{g}^{-1}\right)$ is the $A C Y$ of the residues of dye sorghum leaf sheaths and $28.7\left(\mathrm{mg} \mathrm{g}^{-1}\right)$ is the ACY of the dye sorghum leaf sheaths.

The traditional extraction methods were reproduced in duplicate in the laboratory. The watery extracts were analysed for their apigeninidin and phenolic acid (4-hydroxybenzoic acid and $p$-coumaric acid) contents as well as for their total colour density (TCD). A control was used to evaluate the efficiency of pigment extraction when kanwu and a heating treatment were not applied.

\section{Determination of total phenolic, anthocyanin and apigeninidin contents and TCD}

The phenolic compounds were extracted from dried samples of leaf sheaths and dyed koko using the acidified methanolic $(10 \mathrm{~mL}$ $\mathrm{L}^{-1} \mathrm{HCl} /$ methanol) extraction procedure as described by Kayodé et al..$^{5}$ All extracts were directly used to determine the TPC, ACY, apigeninidin and phenolic acid contents.

The TPC was measured by the modified Folin-Ciocalteu method of Singleton and Rossi ${ }^{20}$ as described by Kayodé et al. ${ }^{15}$ Gallic acid was used as standard. The results were expressed as mg gallic acid equivalent $\mathrm{g}^{-1}$ sample dry matter (DM) for samples of leaf sheaths or mg gallic acid equivalent $\mathrm{mL}^{-1}$ for the sorghum biocolorant.

The ACY was measured at $525 \mathrm{~nm}$ using the method described by Abdel-Aal and Hucl. ${ }^{21}$ The results were expressed as $\mathrm{mg}$ cyanidin-3-glucoside equivalent $\mathrm{g}^{-1}$ sample DM for samples of leaf sheaths or $\mu$ g cyanidin-3-glucoside equivalent $\mathrm{mL}^{-1}$ for the sorghum biocolorant.

The anthocyanin and phenolic acid compositions were analysed using an Ultimate 3000 RS high-performance liquid chromatography (HPLC) system equipped with a DAD-3000 RS diode array detector and an LPG- 3000 RS quaternary pump (Thermo Scientific 
Dionex, Amsterdam, The Netherlands). The extracts were mixed with $100 \mathrm{~mL} \mathrm{~L}^{-1}$ formic acid $(1: 1 \mathrm{v} / \mathrm{v})$ and filtered through a $0.2 \mu \mathrm{m}$ RC filter. A Polaris $5 \mathrm{C} 18-\mathrm{A}$ column $(150 \mathrm{~mm} \times 4.6 \mathrm{~mm}$; Varian, Palo Alto, CA, USA) was used at $25^{\circ} \mathrm{C}$. The flow rate was $1 \mathrm{~mL}$ $\mathrm{min}^{-1}$. The mobile phase consisted of (A) $100 \mathrm{~mL} \mathrm{~L}^{-1}$ formic acid in Milli-Q water and (B) methanol. The elution programme was as follows: $0-20 \mathrm{~min}$, from 5 to $60 \% \mathrm{~B} ; 20-35 \mathrm{~min}$, from 60 to $100 \% \mathrm{~B} ; 25-30 \mathrm{~min}, 100 \% \mathrm{~B} ; 30-31 \mathrm{~min}$, from 100 to $5 \% \mathrm{~B}$; $31-35 \mathrm{~min}, 5 \% \mathrm{~B}$. UV-visible spectra were recorded in the wavelength range $220-700 \mathrm{~nm}$. Apigeninidin, 4-hydroxybenzoic acid and $p$-coumaric acid were monitored at 480, 260 and $280 \mathrm{~nm}$ respectively. Standards of apigeninidin (Extrasynthese, Genay, France), 4-hydroxybenzoic acid (Sigma Aldrich, Zwijndrecht, The Netherlands) and $p$-coumaric acid (Sigma Aldrich) allowed identification and quantification.

The watery extracts of dye sorghum leaf sheaths $(1 \mathrm{~mL})$ were diluted by addition of demi water $(14 \mathrm{~mL})$ and used to measure the TCD according to Turfan et al. ${ }^{22}$

\section{Determination of colour parameters and imaging of extracts}

A volume of $12 \mathrm{~mL}$ of sorghum colorant was poured into a cylindrical glass cuvette of $3.3 \mathrm{~cm}$ inner diameter and $2.2 \mathrm{~cm}$ inner height. The colour was measured on an extract of $1.4 \mathrm{~cm}$ height with a spectrocolorimeter (ColorFlex, HunterLab, Reston, VA, USA) (illuminant $D$ 65) in reflective mode against a white background. ${ }^{23}$ The values of lightness index $\left(L^{*}\right)$, redness index $\left(a^{*}\right)$ and yellowness index $\left(b^{*}\right)$ were recorded. The chroma $\left(C^{*}\right)$ and hue angle $\left(h^{\circ}\right)$ were calculated as follows ${ }^{24}$ :

$$
\begin{gathered}
C^{*}=\left[\left(a^{*}\right)^{2}+\left(b^{*}\right)^{2}\right]^{1 / 2} \\
h^{\circ}=\tan ^{-1}\left(b^{*} / a^{*}\right)
\end{gathered}
$$

In addition, the watery extracts and their dilutions were poured into $1 \mathrm{~cm}$ pathway cuvettes and their images were taken with an Olympus Stylus camera (SP-820UZ, Tokyo, Japan) in a cabin lit by four 36 W lamps.

\begin{abstract}
Statistical analysis
The data collected on the characterisation of dye sorghum leaf sheaths, on the monitoring of the extraction method and on the TPC, ACY, TCD and colour parameters $\left(L^{*}, a^{*}, b^{*}, C^{*}\right.$ and $\left.h^{\circ}\right)$ were analysed using SPSS 16.0 (SPSS Inc., Chicago, IL, USA). The difference between the extraction methods was analysed with (i) one-way analysis of variance (ANOVA) followed by post hoc tests or, when then the normality tests failed, by (ii) Kruskal-Wallis and Mann-Whitney pairwise tests. The survey data collected on the extraction methods and the applications of sorghum colorant were compiled using Sphinx Plus2 Version 4.5 (Le Sphinx Développement, Chavanod, France) for survey management.
\end{abstract}

\section{RESULTS \\ Traditional extraction of pigments from dye sorghum leaf sheaths}

The dye sorghum pigments are traditionally extracted from the plant leaf sheaths using three methods, i.e. cool alkaline extraction, hot alkaline extraction and hot aqueous extraction (Fig. 1). In all extraction scenarios, the dye extraction technique started by a manual trituration of the leaf sheaths in water at room temperature. The trituration time applied for $1 \mathrm{~kg}$ of leaf sheaths during a cool alkaline extraction was $2 \mathrm{~h}$, which was at least three times longer than the time needed for the hot extraction methods. In the alkaline extraction method, kanwu (an alkaline rock salt) was used during the trituration of the leaf sheaths. The role of the kanwu was to facilitate the extraction of the pigment from the sheaths. For $1 \mathrm{~kg}$ of leaf sheaths, $100-180 \mathrm{~g}$ of kanwu was used for cool alkaline extraction, while 40-140 g of kanwu was used for hot alkaline extraction (Fig. 1). During hot extraction, the mixture of water and triturated leaf sheaths was heated gradually on a wood fire to reach a temperature of $86^{\circ} \mathrm{C}$ at a heating speed of $0.05^{\circ} \mathrm{C}$ $\mathrm{s}^{-1}$. When the processor considered the colour of the water red enough, the heating was stopped. The watery dye extract was then filtered with a sieve $(250 \mu \mathrm{m})$ to remove the plant residues and was ready for use.

\section{Characteristics of dye sorghum leaf sheaths and their extracts} The mean TPC and ACY in dye sorghum leaf sheaths from the local markets of the study areas were 82.6 and $28.6 \mathrm{mg} \mathrm{g}^{-1} \mathrm{DM}$ respectively. Table 1 presents the TPC and ACY in the watery extracts using different extraction methods as well as the TPC and $A C Y_{n e}$, which were recovered from the leaf sheaths after extraction. Although the TPC was similar in the watery extracts $\left(0.2 \mathrm{mg} \mathrm{mL}^{-1}\right)$, the ACY was highest in cool alkaline extracts at $228.5 \mu \mathrm{g} \mathrm{mL}^{-1}$ (Table 1). This quantity was four to six times higher than the concentration of anthocyanins in the extracts from the other extraction methods. The lowest ACY $\left(43.9 \mu \mathrm{g} \mathrm{mL}^{-1}\right)$ was measured in hot aqueous extracts. After extraction, no differences between methods were observed on the $T P C_{n e}$ and $A C Y_{n e}$ in the residues. Significant amounts of pigments $(71.9 \%$ of the TPC and $82.6 \%$ of the $A C Y$ ) remained in the leaf sheath residues.

As can be seen in Table 2, the alkaline extraction methods were the best performing methods for apigeninidin extraction, because up to $152 \mu \mathrm{g} \mathrm{mL}^{-1}$ of apigeninidin was found in the cool and hot alkaline extracts against $46.6 \mu \mathrm{g} \mathrm{mL}^{-1}$ in the hot aqueous extract. The $\mathrm{pH}$ of the alkaline extract was around 8-9, whereas it remained at 7 in the non-alkaline extract and in the control. The heat treatment led to a significant reduction in the ACY in the hot alkaline extract (Table 1), while the apigeninidin content was not affected. A higher content of 4-hydroxybenzoic acid was measured with hot alkaline extraction. The extraction methods did not affect the $p$-coumaric acid content.

Table 3 presents the TCD and colour parameters of the watery extracts. The alkaline methods (cool alkaline and hot alkaline) had a higher TCD. This suggests that alkaline extraction results in a more intense colour. In addition, the application of a heat treatment did not affect the intensity of the colour of the hot alkaline extract. The hot aqueous extraction was the method with the lowest TCD. Nevertheless, this TCD was still better than the control. A thermal treatment provided better colouring properties than a non-thermal treatment when no extraction aid (such as kanwu) was used. In addition, Fig. 2 illustrates (i) the higher colour intensity of the alkaline extraction methods and (ii) the lower colour intensity of the aqueous method compared with the control. The values recorded for $L^{*}, a^{*}$ and $b^{*}$ for the extraction methods were all lower than for the control. This revealed that the watery extracts were too concentrated for colour measurement. Figure 3 presents the chromaticity diagram of the diluted watery extracts. To compare the watery extracts in a chroma range of $42-48$, dilution factors of 0.25 and 0.07 were applied to (i) the hot aqueous extract and (ii) the hot alkaline and cool alkaline extracts respectively. The dilution of the 


\begin{tabular}{|c|c|c|c|}
\hline \multirow[t]{2}{*}{ Unit operations } & \multicolumn{3}{|c|}{ Extraction method } \\
\hline & $\begin{array}{c}\text { Cool alkaline } \\
\text { extraction } \\
(n=3)\end{array}$ & $\begin{array}{c}\text { Hot alkaline } \\
\text { extraction } \\
(n=3)\end{array}$ & $\begin{array}{c}\text { Hot aqueous } \\
\text { extraction } \\
(n=3)\end{array}$ \\
\hline Quantity of leaf sheaths & $1 \mathrm{~kg}$ & $1 \mathrm{~kg}$ & $1 \mathrm{~kg}$ \\
\hline \multirow[t]{2}{*}{ Addition of water [quantity in L] } & $\downarrow$ & $\begin{array}{l}\downarrow \\
\mathrm{x}\end{array}$ & $\begin{array}{l}\downarrow \\
\mathrm{x}\end{array}$ \\
\hline & {$[85.9 \pm 43.9]^{\mathrm{b}}$} & {$[85.4 \pm 46.3]$} & {$[79.5 \pm 42.8]$} \\
\hline \multirow[t]{2}{*}{ Addition of kanwu [quantity in g] } & $\begin{array}{l}\downarrow \\
\mathrm{x}\end{array}$ & $\underset{\mathrm{x}}{\downarrow}$ & \\
\hline & {$[146.6 \pm 41.6]$} & {$[93.2 \pm 50.4]$} & \\
\hline \multirow{3}{*}{ Trituration [duration in min] } & $\downarrow$ & $\downarrow$ & $\downarrow$ \\
\hline & $\mathrm{x}$ & $\mathrm{x}$ & $\mathrm{x}$ \\
\hline & {$[118 \pm 0.0]$} & {$[26 \pm 29]$} & {$[36 \pm 21]$} \\
\hline \multirow{2}{*}{$\begin{array}{l}\text { Heating [speed }\left({ }^{\circ} \mathrm{C} \mathrm{s}^{-1}\right) / \\
\text { temperature reached }\left({ }^{\circ} \mathrm{C}\right) \text { ] }\end{array}$} & & $\begin{array}{l}\downarrow \\
\mathrm{x}\end{array}$ & $\begin{array}{l}\downarrow \\
\mathrm{x}\end{array}$ \\
\hline & & {$[0.05 \pm 0.01 /$} & {$[0.05 \pm 0.02 /$} \\
\hline \multirow{3}{*}{ Filtration } & $\downarrow$ & $\begin{array}{c}86 \pm 22] \\
\downarrow\end{array}$ & $\stackrel{86 \pm 18]}{\downarrow}$ \\
\hline & $\mathrm{x}$ & $\mathrm{x}$ & $\mathrm{x}$ \\
\hline & $\downarrow$ & $\downarrow$ & $\downarrow$ \\
\hline \multirow[t]{2}{*}{ Watery dye extract [yield in $L$ ] } & $\mathrm{x}$ & $\mathrm{x}$ & $\mathrm{x}$ \\
\hline & {$[84.6 \pm 44.2]$} & {$[81.3 \pm 40]$} & {$[75.3 \pm 42.1]$} \\
\hline
\end{tabular}

Figure 1. Process diagrams of three commonly used traditional extraction methods for biocolorants from dye sorghum leaf sheaths. Values are mean \pm standard deviation. Crosses $(\mathrm{x})$ indicate that the unit operation is applied in the particular method.

Table 1. Phenolic and anthocyanin contents in watery extracts and residues according to three extraction methods

\begin{tabular}{|c|c|c|c|c|}
\hline \multirow[b]{2}{*}{ Sample } & \multirow[b]{2}{*}{ Parameter $^{\mathrm{a}}$} & \multicolumn{3}{|c|}{ Extraction method } \\
\hline & & $\begin{array}{c}\text { Cool alkaline } \\
\text { extraction }(n=3)\end{array}$ & $\begin{array}{c}\text { Hot alkaline } \\
\text { extraction }(n=3)\end{array}$ & $\begin{array}{c}\text { Hot aqueous } \\
\text { extraction }(n=3)\end{array}$ \\
\hline \multirow[t]{2}{*}{ Extract } & $\mathrm{TPC}\left(\mathrm{mg} \mathrm{mL}^{-1}\right)$ & $0.3 \pm 0.2 a$ & $0.2 \pm 0.1 a$ & $0.2 \pm 0.0 a$ \\
\hline & $\mathrm{ACY}\left(\mu \mathrm{g} \mathrm{mL}^{-1}\right)$ & $228.5 \pm 93.6 a$ & $50.9 \pm 5.0 \mathrm{~b}$ & $43.9 \pm 8.3 b$ \\
\hline \multirow[t]{4}{*}{ Residue of leaf sheaths } & $\mathrm{TPC}_{\mathrm{ne}}\left(\mathrm{mg} \mathrm{g}^{-1} \mathrm{DM}\right)$ & $99.8 \pm 12.0 \mathrm{a}$ & $89.8 \pm 21.6 a$ & $94.4 \pm 21.9 \mathrm{a}$ \\
\hline & $\% \mathrm{TPC}_{\mathrm{ne}}$ & $76.3 \pm 9.2 a$ & $68.7 \pm 16.5 a$ & $72.2 \pm 16.8 \mathrm{a}$ \\
\hline & $\mathrm{ACY}_{\mathrm{ne}}\left(\mathrm{mg} \mathrm{g}^{-1} \mathrm{DM}\right)$ & $22.6 \pm 1.84 a$ & $20.3 \pm 4.0 \mathrm{a}$ & $22.6 \pm 1.8 a$ \\
\hline & $\% \mathrm{ACY}_{\text {ne }}$ & $85.9 \pm 6.9 a$ & $77.7 \pm 15.3 a$ & $84.2 \pm 6.6 a$ \\
\hline
\end{tabular}

hot aqueous extract with a factor of 0.07 also increased the hue value. Furthermore, the colour parameters of the watery extracts from the hot and cool alkaline methods that were diluted with a factor of 0.07 were close on the chromaticity graph. Therefore the heat treatment did not affect the colour of the alkaline watery extract. In general, the diluted watery extract from dye sorghum leaf sheaths had an orange-red colour.

Cool alkaline extraction was preferred by the majority of the processors because of its good colouring properties and the ease of its application. The yield of extract from cool alkaline extraction was $84.6 \mathrm{~L} \mathrm{~kg}^{-1}$ leaf sheaths (Fig. 1). Indeed, the need of a heat treatment required for hot alkaline and hot aqueous extractions discouraged their use. Consequently, hot extractions are common in processing where a heat treatment of the food and dyeing need to be carried out simultaneously.

\section{Application of sorghum biocolorant in starchy fermented foods: the case of koko}

Maize-based koko is a porridge prepared from ogi, a fermented cereal slurry. ${ }^{25,26}$ It is commonly dyed with sorghum biocolorant to 
Table 2. Apigeninidin and phenolic acid contents of dye sorghum leaf sheath extracts obtained by traditional methods

\begin{tabular}{|c|c|c|c|c|}
\hline \multirow[b]{2}{*}{ Parameter $\left(\mu \mathrm{g} \mathrm{mL}^{-1}\right)$} & \multicolumn{4}{|c|}{ Extraction method } \\
\hline & Control $^{\mathrm{a}}(n=2)$ & $\begin{array}{c}\text { Cool alkaline } \\
\text { extraction }(n=2)\end{array}$ & $\begin{array}{c}\text { Hot alkaline } \\
\text { extraction }(n=2)\end{array}$ & $\begin{array}{l}\text { Hot aqueous } \\
\text { extraction }(n=2)\end{array}$ \\
\hline Apigeninidin & $12.1 \pm 1.3 c$ & $152.0 \pm 21.7 a$ & $131.0 \pm 7.5 \mathrm{a}$ & $46.6 \pm 0.9 b$ \\
\hline 4-Hydroxybenzoic acid & $4.9 \pm 0.2 b$ & $5.1 \pm 0.1 b$ & $6.0 \pm 0.3 a$ & $5.3 \pm 0.3 b$ \\
\hline$p$-Coumaric acid & $3.6 \pm 0.3 a$ & $3.5 \pm 0.3 a$ & $4.1 \pm 0.6 a$ & $3.8 \pm 0.6 a$ \\
\hline
\end{tabular}

Table 3. Total colour density and colour parameters of dye sorghum leaf sheath extracts obtained by traditional methods

\begin{tabular}{|c|c|c|c|c|}
\hline \multirow[b]{2}{*}{ Parameter $^{\mathrm{a}}$} & \multicolumn{4}{|c|}{ Extraction method } \\
\hline & Control $(n=2)$ & $\begin{array}{c}\text { Cool alkaline } \\
\text { extraction }(n=2)\end{array}$ & $\begin{array}{c}\text { Hot alkaline } \\
\text { extraction }(n=2)\end{array}$ & $\begin{array}{c}\text { Hot aqueous } \\
\text { extraction }(n=2)\end{array}$ \\
\hline TCD & $4.6 \pm 0.0 c$ & $48.9 \pm 0.4 a$ & $50.6 \pm 0.0 a$ & $15.5 \pm 0.1 b$ \\
\hline$L^{*}$ & $12.0 \pm 0.8 a$ & $0.5 \pm 0.2 c$ & $0.7 \pm 0.1 c$ & $10.2 \pm 0.6 b$ \\
\hline$a^{*}$ & $28.8 \pm 0.2 \mathrm{a}$ & $1.5 \pm 0.1 c$ & $1.8 \pm 0.1 \mathrm{c}$ & $19.8 \pm 0.5 b$ \\
\hline$b^{*}$ & $17.8 \pm 0.3 a$ & $-0.1 \pm 0.1 c$ & $0.3 \pm 0.4 c$ & $13.4 \pm 0.2 b$ \\
\hline
\end{tabular}

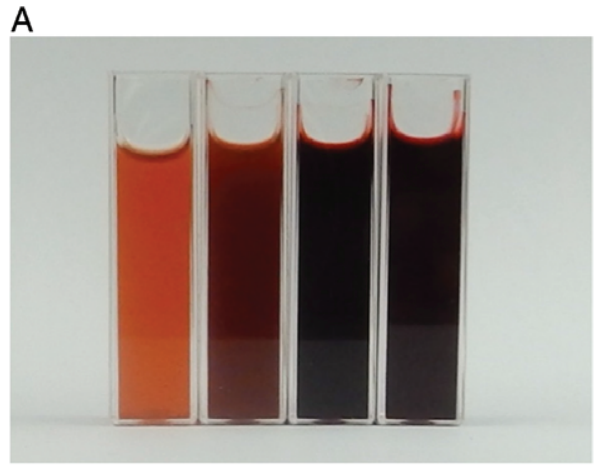

B

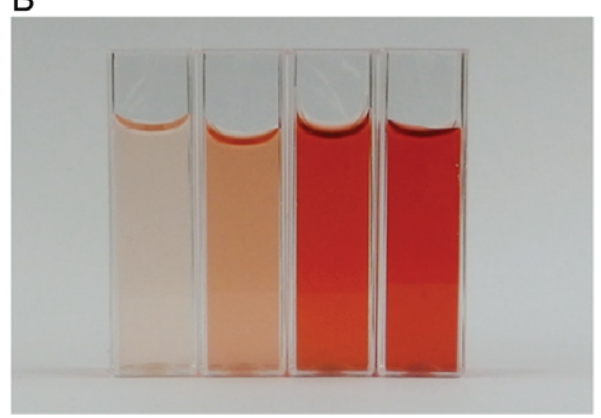

Figure 2. Images of (A) control, hot aqueous extract, hot alkaline extract and cool alkaline extract (from left to right) and (B) their diluted samples (dilution factor 0.07).

give it a red colour. ${ }^{5}$ The dyeing could be performed before or after the fermentation step. Dyeing is applied after the fermentation step by $71 \%$ of the processors.

Two methods were used by processors to produce dyed maize-based koko: one based on the use of the whole dye sorghum leaf sheaths and one based on the use of the watery extract of dye sorghum leaf sheaths. The use of the whole dye sorghum leaf sheaths in the processing of dyed koko was described by $29 \%$ of the processors. This method consisted of wet grinding of maize with dye sorghum leaf sheaths. The wet flour thereby obtained had a colour similar to the red sorghum. This red flour was sieved and allowed to ferment spontaneously for 1-3 days at room temperature. The starchy sediment was then cooked to obtain dyed maize-based koko. This method was the only one in which the dye sorghum leaf sheaths underwent fermentation. This unit operation is efficient in depolymerisation of phenolic compounds, including anthocyanins, in the processing of koko. ${ }^{17,27}$ Instead of using the whole leaf sheaths, the watery extract could also be used. In that case, maize grains were processed from the soaking to the fermentation step without adding dye sorghum leaf sheaths. When the fermentation was completed and the starchy sediment ready for cooking, a watery extract from dye sorghum leaf sheaths was produced using hot aqueous extraction (33\% of the processors) or cool alkaline extraction (38\% of the processors). This watery dye extract was added during cooking to obtain dyed koko.

The TPC of the samples of dyed koko varied from 0.26 to $1.23 \mathrm{mg}$ $\mathrm{g}^{-1}$ DM with a mean value of $0.64 \mathrm{mg} \mathrm{g}^{-1} \mathrm{DM}$, while the ACY varied from 0.1 to $1.0 \mathrm{mg} \mathrm{g}^{-1} \mathrm{DM}$ with a mean value of $0.23 \mathrm{mg} \mathrm{g}^{-1} \mathrm{DM}$.

\section{DISCUSSION}

The pigment profile of dye sorghum leaf sheaths found in the local markets of the study areas resembled the data reported by Kayodé et al., ${ }^{5}$ who found a TPC of $95.5 \mathrm{mg} \mathrm{g}^{-1}$ DM and an ACY of $27.1 \mathrm{mg} \mathrm{g}^{-1} \mathrm{DM}$. The results imply similar pigment profiles from samples from different study areas and from different seasons. Such stability of natural pigment profiles is not common, because natural sources of food colorants are commonly characterised by substantial variations. ${ }^{28}$ 


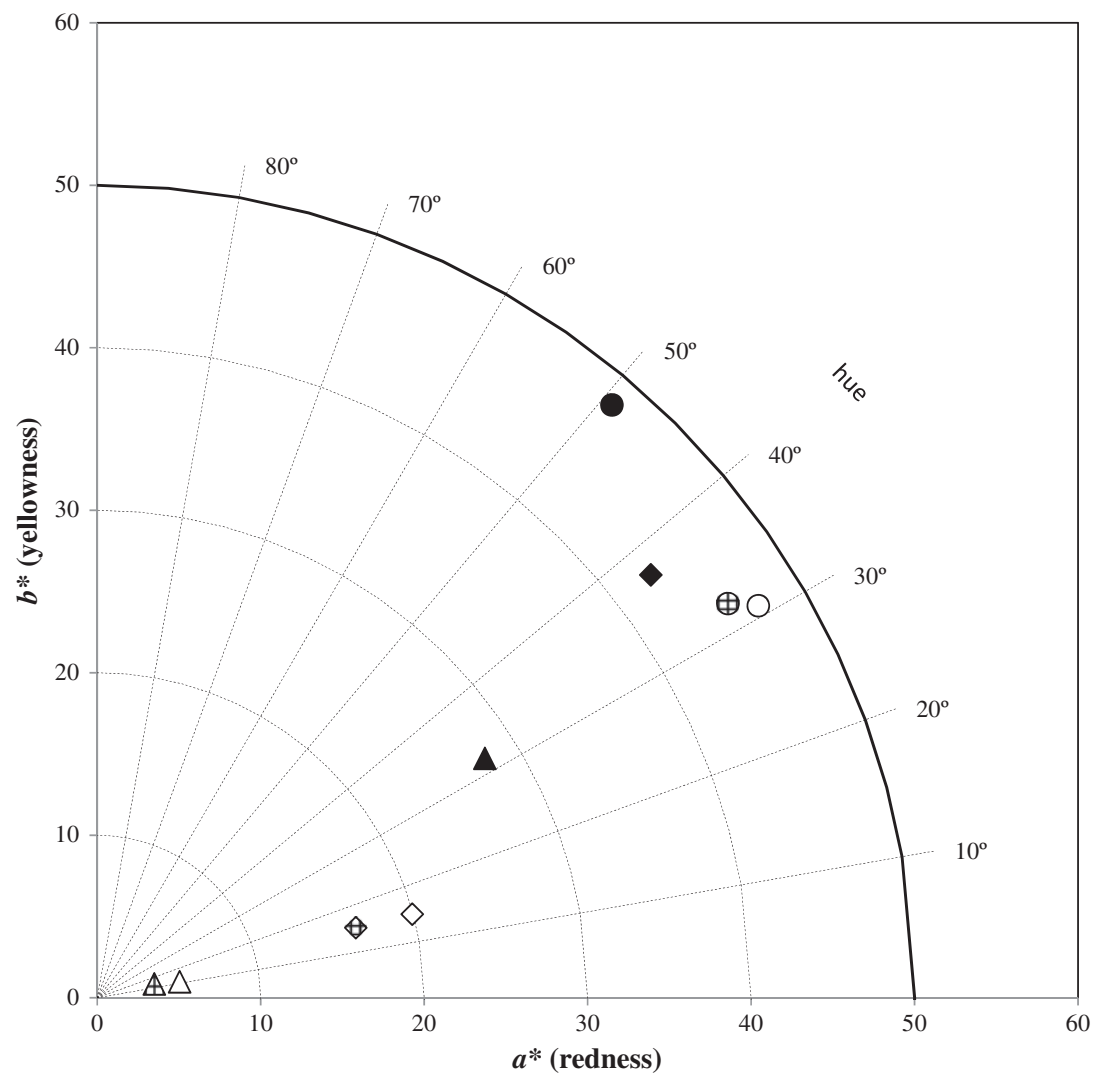

Figure 3. Chromaticity diagram of watery extracts from hot aqueous (black), hot alkaline (tiled) and cool alkaline (white) extractions with dilution factors of 0.07 (circle), 0.25 (diamond) and 0.5 (triangle).

The merit of the watery extraction methods is their selectivity for water-soluble pigments such as anthocyanins. However, overall, the extraction of sorghum colorant using traditional methods resulted in low extraction rates, leaving the discarded plant residues still rich in pigments. Improvement and optimisation of the watery extraction methods are needed to increase the yield of this natural colorant. The use of leaf sheath powder could be the first improvement to the traditional methods. Indeed, particle size is crucial for a good extractability and could result in a lower amount of leaf sheaths needed. ${ }^{29}$ In addition, low-cost and energy-saving methods for sorghum biocolorant extraction could be designed by optimising $\mathrm{pH}$, temperature and time. ${ }^{30}$ This could launch rural communities in Benin in an eco-friendly production of sorghum biocolorant for food industries.

The application of a heat treatment temperature and a high $\mathrm{pH}$ affected the anthocyanin recovery during the hot aqueous and hot alkaline extraction processes and could therefore explain the lower amount of anthocyanins measured in hot alkaline and aqueous extracts. ${ }^{15,31,32}$ Alkaline extraction methods were efficient for obtaining apigeninidin, because alkaline treatments promoted the release of bound phenolics present in the leaf sheaths. ${ }^{33}$ Significant amounts of apigeninidin were recovered in both cool and hot alkaline extracts at comparable levels. This finding provided additional information on the thermal stability of apigeninidin in the $\mathrm{pH}$ range $7-9 .{ }^{12}$ The higher apigeninidin content in alkaline extracts (cool and hot) compared with the aqueous extract supports an uncommon response of apigeninidin to the alkaline treatment. In general, alkaline treatments cause degradation of anthocyanins with a loss of $25-35 \%$ of anthocyanins at $\mathrm{pH} 8,^{34}$ but in our study a higher apigeninidin content was measured in the alkaline extracts of dye sorghum as compared with the aqueous extract, indicating the stability of apigeninidin in a watery extract at alkaline conditions. The absence of hydroxyl on the third position of 3-deoxyanthocyanidins (e.g. apigeninidin) could confer resistance to ring fission when a high $\mathrm{pH}$ and/or a heat treatment are applied. ${ }^{10,12}$ The stability of apigeninidin from alkaline extracts to food acidulants and to common food processing heat treatments (i.e. pasteurisation, cooking and sterilisation) still needs to be investigated further for its potential usability in foods.

The shade of the diluted watery extract of dye sorghum $\left(h^{\circ}\right.$ value between 30 and 50 ) was less red than for commercial natural colorants such as elderberry $\left(h^{\circ}=17.2\right)$, red carrot concentrate $\left(h^{\circ}=15.5\right)$, red grape skin extract $\left(h^{\circ}=17.2\right)$ and hibiscus $\left(h^{\circ}=13.9\right) .{ }^{24}$ Nevertheless, few natural colorants are known to possess an orange-red colour at high $\mathrm{pH}$ at high dilution factors (such as the 0.07 in this research). This indicates a low dose response for the watery extract from dye sorghum leaf sheaths compared with other natural extracts. ${ }^{24}$ In addition, the diluted watery extract of dye sorghum leaf sheaths had a hue value comparable to some synthetic food colorants (e.g. red allura, carmoisine and ponceau $4 \mathrm{R}$ ) that have a hue value range between 30 and $50 .^{35}$ Sorghum biocolorant could therefore potentially replace those artificial colorants.

The data on the 4-hydroxybenzoic and $p$-coumaric acids provided information on the effect of the extraction method on two main groups of phenolic acids present in cereals (i.e. the hydroxybenzoic acids and hydroxycinnamic acids). ${ }^{36}$ Our findings suggest that the amount of hydroxycinnamic acids (e.g. $p$-coumaric acid) in the extracts is comparable for the three extraction methods, whereas the amount of hydroxybenzoic acids 
(e.g. 4-hydroxybenzoic acid) could be increased by hot alkaline extraction. The effect of alkaline and non-alkaline extractions on the hydroxybenzoic acid and hydroxycinnamic acid contents still needs to be investigated further.

Koko is a popular cereal-based food described as of low nutritional value for children. ${ }^{17}$ It was selected as a model food because its processing involves fermentation and cooking. Fermentation potentially induces changes in the amount of phenolics, the antioxidant activity, the bioavailability of nutrients and the product pH. 27,37,38 The mean TPC of sorghum-based koko found by Kayodé et al. ${ }^{17}$ in Benin was $2.12 \mathrm{mg} \mathrm{g}^{-1}$ DM. Apparently, the TPC of dyed maize-based koko was lower than the TPC of sorghum-based koko. A high amount of total reactive hydroxyls is measured in fermented foods using the method of Singleton and Rossi, ${ }^{20}$ possibly because of the hydrolysis of condensed phenols during the fermentation. ${ }^{39}$ The limited bioavailability of micronutrients such as iron and zinc in cereal-based infant foods is a major concern in transition countries such as Benin..$^{40,41}$ In this respect, attention for the effects of sorghum colorant on the micronutrient bioavailability in infant foods is relevant. Consequently, future research is recommended on the bioavailability of micronutrients (e.g. the minerals iron and zinc) and antioxidant activity in dyed foods.

\section{CONCLUSION}

The natural colorant from dye sorghum leaf sheaths is rich in apigeninidin, which confers an orange-red colour to this extract. The extraction of this pigment is best in alkaline conditions. Future research on sorghum biocolorant should focus on the improvement of the traditional methods of pigment extraction, the stability of apigeninidin from alkaline extracts, the bioavailability of micronutrients such as minerals (iron and zinc) and antioxidant activity in dyed foods.

\section{ACKNOWLEDGEMENT}

This research was funded by the Netherlands Organization for International Cooperation in Higher Education (grant award CF8188/2012).

\section{REFERENCES}

1 Chattopadhyay P, Chatterjee S and Sen SK, Biotechnological potential of natural food grade biocolorants. Afr J Biotechnol 7:2972-2985 (2008).

2 Downham A and Collins $\mathrm{P}$, Colouring our foods in the last and next millennium. Int J Food Sci Technol 35:5-22 (2000).

3 Wissgott $U$ and Bortlik K, Prospects for new natural food colorants. Trends Food Sci Technol 7:298-302 (1996).

4 Balole TV and Legwaila GM, Sorghum bicolor, in Plant Resources of Tropical Africa 3. Dyes and Tannins, ed. by Jansen PCM and Cardon D. PROTA Foundation, Wageningen, pp. 146-155 (2005).

5 Kayodé APP, Nout MJR, Linnemann AR, Hounhouigan JD, Berghofer E and Siebenhandl-Ehn S, Uncommonly high levels of 3-deoxyanthocyanidins and antioxidant capacity in the leaf sheaths of dye sorghum. J Agric Food Chem 59:1178-1184 (2011).

6 Awika JM and Rooney LW, Sorghum phytochemicals and their potential impact on human health. Phytochemistry 65:1199-1221 (2004).

7 Wallace TC and Giusti MM, Anthocyanins. Adv Nutr 6:620-622 (2015).

8 Awika JM, Behavior of 3-deoxyanthocyanidins in the presence of phenolic copigments. Food Res Int 41:532-538 (2008).

9 Awika JM, Rooney LW and Waniska RD, Properties of 3-deoxyanthocyanins from sorghum. J Agric Food Chem 52:4388-4394 (2004)

10 Ojwang $L$ and Awika JM, Effect of pyruvic acid and ascorbic acid on stability of 3-deoxyanthocyanidins. J Sci Food Agric 88:1987-1996 (2008).
11 Geera B, Ojwang LO and Awika JM, New highly stable dimeric 3-deoxyanthocyanidin pigments from Sorghum bicolor leaf sheath. J Food Sci 77:C566-C572 (2012).

12 Yang $\mathrm{L}$, Dykes $\mathrm{L}$ and Awika JM, Thermal stability of 3-deoxyanthocyanidin pigments. Food Chem 160:246-254 (2014).

13 Cevallos-Casals BA and Cisneros-Zevallos L, Stability of anthocyanin-based aqueous extracts of Andean purple corn and red-fleshed sweet potato compared to synthetic and natural colorants. Food Chem 86:69-77 (2004).

14 Sims $\mathrm{C}$ and Morris J, Effects of $\mathrm{pH}$, sulfur dioxide, storage time, and temperature on the color and stability of red muscadine grape wine. Am J Enol Vitic 35:35-39 (1984).

15 Kayodé APP, Bara CA, Dalodé-Vieira G, Linnemann AR and Nout MJR, Extraction of antioxidant pigments from dye sorghum leaf sheaths. LWT - Food Sci Technol 46:49-55 (2012).

16 Madodé YE, Keeping local foods on the menu: a study on the small-scale processing of cowpea. Thesis, Wageningen University (2012).

17 Kayodé APP, Akogou FUG, Hounkpatin WA and Hounhouigan JD, Effets des procédés de transformation sur la valeur nutritionnelle des formulations de bouillies de complément à base de sorgho. Int J Biol Chem Sci 6:2192-2201 (2012).

18 Aïssi VM, Soumanou MM, Bankolè $H$, Toukourou F and de Souza CA, Evaluation of hygienic and mycological quality of local cheese marketed in Benin. Aust J Basic Appl Sci 3:2397-2404 (2009).

19 Quisumbing AR, Brown LR, Feldstein HS, Haddad L and Peña C, Women: the Key to Food Security. International Food Policy Research Institute, Washington, DC (1995).

20 Singleton VL and Rossi JA, Colorimetry of total phenolics with phosphomolybdic-phosphotungstic acid reagents. Am J Enol Vitic 16:144-158 (1965)

21 Abdel-Aal ESM and Hucl P, A rapid method for quantifying total anthocyanins in blue aleurone and purple pericarp wheats. Cereal Chem 76:350-354 (1999).

22 Turfan Ö, Türkyılmaz M, Yemiş O and Özkan M, Anthocyanin and colour changes during processing of pomegranate (Punica granatum L., cv. Hicaznar) juice from sacs and whole fruit. Food Chem 129:1644-1651 (2011).

23 Tanoue N, Soeno K, Kawasaki K and Atsuta M, Influence of acidulated phosphate fluoride solution on the color stability of indirect composites. J Prosthet Dent 92:343-347 (2004).

24 Castellar MR, Obón JM and Fernández-López JA, The isolation and properties of a concentrated red-purple betacyanin food colourant from Opuntia stricta fruits. J Sci Food Agric 86:122-128 (2006).

25 Nago MC, Hounhouigan JD, Akissoe N, Zanou E and Mestres C, Characterization of the Beninese traditional ogi, a fermented maize slurry: physicochemical and microbiological aspects. Int J Food Sci Technol 33:307-315 (1998).

26 Blandino A, Al-Aseeri M, Pandiella S, Cantero D and Webb C, Cereal-based fermented foods and beverages. Food Res Int 36:527-543 (2003)

27 Wiczkowski W, Szawara-Nowak D and Topolska J, Changes in the content and composition of anthocyanins in red cabbage and its antioxidant capacity during fermentation, storage and stewing. Food Chem 167:115-123 (2015).

28 Mapari SA, Nielsen KF, Larsen TO, Frisvad JC, Meyer AS and Thrane U, Exploring fungal biodiversity for the production of water-soluble pigments as potential natural food colorants. Curr Opin Biotechnol 16:231 - 238 (2005).

29 Brewer LR, Kubola J, Siriamornpun S, Herald TJ and Shi YC, Wheat bran particle size influence on phytochemical extractability and antioxidant properties. Food Chem 152:483-490 (2014).

30 Rajha HN, El Darra N, Vorobiev E, Louka N and Maroun RG, An environment friendly, low-cost extraction process of phenolic compounds from grape byproducts. Optimization by multi-response surface methodology. Food Nutr Sci 4:650-659 (2013).

31 Kirca A, Özkan M and Cemeroğlu B, Effects of temperature, solid content and $\mathrm{pH}$ on the stability of black carrot anthocyanins. Food Chem 101:212-218 (2007)

32 Underhill S and Critchley C, Anthocyanin decolorisation and its role in lychee pericarp browning. Anim Prod Sci 34:115-122 (1994).

33 White BL, Howard LR and Prior RL, Release of bound procyanidins from cranberry pomace by alkaline hydrolysis. J Agric Food Chem 58:7572-7579 (2010).

34 Rodriguez-Saona LE, Wrolstad RE and Pereira C, Glycoalkaloid content and anthocyanin stability of alkaline treatment of red-fleshed potato extracts. J Food Sci 64:445-450 (1999). 
35 Arocas A, Varela P, González-Miret ML, Salvador A, Heredia FJ and Fiszman SM, Differences in colour gamut obtained with three synthetic red food colourants compared with three natural ones: $\mathrm{pH}$ and heat stability. Int J Food Prop 16:766-777 (2013).

36 Wang T, He F and Chen G, Improving bioaccessibility and bioavailability of phenolic compounds in cereal grains through processing technologies: a concise review. J Funct Foods 7:101-111 (2014).

37 Katina K, Liukkonen K-H, Kaukovirta-Norja A, Adlercreutz H, Heinonen S-M, Lampi A-M et al., Fermentation-induced changes in the nutritional value of native or germinated rye. J Cereal Sci 46:348-355 (2007).

38 Kayodé APP, Mertz C, Guyot JP, Brat P and Mouquet-Rivier C, Fate of phytochemicals during malting and fermentation of type III tannin sorghum and impact on product biofunctionality. J Agric Food Chem 61:1935-1942 (2013)

39 Kayodé APP, Hounhouigan JD and Nout MJR, Impact of brewing process operations on phytate, phenolic compounds and in vitro solubility of iron and zinc in opaque sorghum beer. LWT - Food Sci Technol 40:834-841 (2007).

40 Mitchikpè ECS, Dossa RA, Ategbo E-AD, van Raaij JM, Hulshof PJ and Kok FJ, The supply of bioavailable iron and zinc may be affected by phytate in Beninese children. J Food Compos Anal 21:17-25 (2008).

41 Tufts HR, Harris CS, Bukania ZN and Johns T, Antioxidant and anti-inflammatory activities of Kenyan leafy green vegetables, wild fruits, and medicinal plants with potential relevance for kwashiorkor. Evid Based Compl Altern Med 2015:807158 (2015). 